Elsevier required licence: (C) <2018>. This manuscript version is made available under the CC-BY-NCND 4.0 license http://creativecommons.org/licenses/by-nc-nd/4.0/

The definitive publisher version is available online at

[https://linkinghub.elsevier.com/retrieve/pii/S187151921830739X] 
Getting evidence into practice - Managing hares and tortoises, Women and Birth, 2018, 31 (6), pp. $431-432$

\title{
Getting evidence into practice - Managing hares and tortoises
}

\author{
Caroline Homer
}

Co-Program Director, Maternal and Child Health, Burnet Institute, Victoria. Melbourne

Distinguished Visiting Professor, University of Technology Sydney, New South Wales, Australia

One of the challenges of being a health care provider in any country is working out what research to respond to and translate into everyday practice and how quickly. Translating evidence into practice generally seems to take a long time - it has been suggested it generally takes about 17 years before evidence is mainstreamed into clinical practice (1). In maternity care, that probably rings true although I find it fascinating that some evidence is accepted quickly while others seem to take forever. I call this the hare and the tortoise of translation - things that get taken up quickly are hares which those that lumber along, sometimes for decades, are tortoises - hopefully they get there at some point. I have been again struck by this with the recent publication of the ARRIVE trial (2) which we wrote about in my last Editorial (3) and now the AFFIRM trial (4). The former seems to be getting translated into practice almost immediately while question still exist about the latter.

This challenge of getting evidence into practice goes back a long way. One early example was the evidence that scurvy could be treated with citrus fruit. James Lind, a Scottish surgeon in the Royal Navy did an experiment with 12 participants in 1749. The results showing that it seemed to work were published in the book, A treatise of the scurvy (5) in 1753, and was largely ignored. It was thought that scurvy was a disease of putrefaction. Despite this, on Captain's Cook's first voyage in 1768 , citrus and other fruits containing Vitamin C were carried on board although this was not routine. Years went by before the Admiralty in 1795 recommended that lemon juice should be issued routinely to the whole fleet and this become routine in the early 1800 s. Sixty years to get evidence into practice - certainly a tortoise.

More recently, the use of corticosteroids in women at risk of a preterm birth is often cited as an example of the 20 year time frame of getting evidence into practice. The earliest studies were in sheep in New Zealand in the late 1960s (6) which led to the first randomised controlled trial (RCT) in humans published in 1972 (7) and then a systematic review in 1990 (8). The forest plot for the reduction of neonatal respiratory distress in this review become the logo of the Cochrane Collaboration and is familiar to us all. By the 2000s, in many high income countries, a single dose of corticosteroids given to women less than 32 weeks gestation who are at risk of giving birth was becoming commonplace, however coverage remains low in low- and middle-income countries (9).

Some other practice changes overnight and are the 'hare' of evidence into practice. An example of this is the impact that the Term Breech Trial (10) had on vaginal breech births. Colleagues of mine can remember where they were when the trial results were released in 2000 and recall how suddenly, by the next day, practice changed. Suddenly, many clinicians were happy to accept the evidence of one RCT immediately and without hesitation. Many critiques of the trial appeared in the academic literature and online but this made little difference. Subsequent research has suggested that vaginal breech in the right circumstances for the right women with the right providers can be 
safe but it remains a challenge for many women to access a vaginal breech birth $(11,12)$. The hare had well and truly hopped off and slowing in down has taken more than a decade. The tide is shifting and many health services in Australia have dedicated breech clinics and midwives and doctors who are willing to enable women to have a vaginal breech birth. There are also government policies in some Australia states supporting women who want a vaginal breech birth (13). It is a slow process though and women in many high income countries have little to few options.

My final example is midwifery continuity of care - a complex intervention with now a very strong evidence-base but currently is a tortoise. Maybe we can speed it up a bit?

The first RCT evidence for midwifery continuity of care was from Caroline Flint in 1989 (14). More studies followed soon after - from Australia, the UK and Canada. Alongside were government reviews and reports into maternity care all calling for more access to midwifery continuity of care. The first systematic review was published in 2008 (15) and updated in 2013 and again in 2016 (16) and there is clear policy in many countries including Better Births in England (17). The World Health Organization recommends midwife-led continuity-of-care models should be implemented for pregnant women in settings with well functioning midwifery programs (18).

Despite all this, in countries like Australia, the proportion of women having access to midwifery continuity of care remains low. One Australian study has estimated that only one third of 149 maternity managers who were surveyed reported that their hospital midwifery continuity of care, and an estimated eight percent of women received this type care at the time of the survey, most of whom were considered to be of 'low obstetric risk (19). On social media, in blogs and other media, women consistently report wanting midwifery continuity of care, our students and new graduates (20) say they want to work in this way but it remains a tortoise in many places.

Addressing the hares and tortoises is something we all must identify and take responsibility for. Findings that agree with our own beliefs and biases seem easier to translate into everyday practice. Findings which support our fears get translated quickly (e.g. we stop supporting vaginal breech births overnight) while interventions that are complex, like midwifery continuity of care, often languish in the pit of challenge.

Our journal publishes the evidence but it is in the hands of our readers to make change happen in an effective timeframe. We need to plan implementation as early as possible in our research and use principles and designs from the discipline of Implementation Science to bring about change. We must engage and work with women as consumers and end users in planning our research ensuring that we study what matters and will make a difference. We must work with providers, policy makers and health service leaders and planners in the identification and design of research and the process of implementation. Getting evidence into practice is usually complex - many of our interventions are also complex - so we must address challenges on multiple levels, be open to identifying road-blocks and mediators, finding champions and leaders and monitoring and auditing progress.

I challenge you, as the readers of Women and Birth and practitioners in maternity care, to find the 'tipping point' where evidence-based practice is translated and transferred into common practice in maternity care. We need to make sure the high level evidence is embedded in practice in a timely manner, and more importantly, we need to stop doing things that are shown to be not based on evidence. This is a worthy challenge for us that will improve outcomes for mothers and babies in all our settings. 


\section{References}

1. Morris Z, Wooding S, Grant J. The answer is 17 years, what is the question: understanding time lags in translational research. Journal of the Royal Society of Medicine.

2011;104(12):510-20.

2. Grobman W, Rice M, Reddy U, Tita A, Silver R, Mallett G, et al. Labor Induction versus Expectant Management in Low-Risk Nulliparous Women. New England Journal of Medicine. 2018;379:513-23.

3. Davies-Tuck M, Wallace E, Homer C. Why ARRIVE should not thrive in Australia. Women and Birth. 2018;31(5):339-40.

4. Norman J, Heazell A, Rodriguez A, Weir C, Stock S, Calderwood C, et al. Awareness of fetal movements and care package to reduce fetal mortality (AFFIRM): a stepped wedge, clusterrandomised trial. The Lancet. 2018;Online.

5. $\quad$ Lind J. A treatise of the scurvy. Edinburgh: The James Lind Library; 1753.

6. Liggins $\mathrm{G}$. Premature delivery of foetal lambs infused with glucocorticoids. The Journal of endocrinology. 1969;45(4):515-23.

7. Liggins $\mathrm{G}$, Howie R. A controlled trial of antepartum glucocorticoid treatment for prevention of the respiratory distress syndrome in premature infants. Pediatrics. 1972;50(4):515-25.

8. Crowley P, Chalmers I, Keirse M. The effects of corticosteroid administration before preterm delivery: an overview of the evidence from controlled trials. Br J Obstet Gynaecol. 1990;97(1):11-25.

9. Liu G, Segrè J, Gülmezoglu A, Mathai M, Smith J, Hermida J, et al. Antenatal corticosteroids for management of preterm birth: a multi-country analysis of health system bottlenecks and potential solutions. BMC Pregnancy and Childbirth. 2015;15(Suppl 2):S3-S.

10. Hannah ME, Hannah WJ, Hewson S, Hodnett ED, Saigal S, Willan AR. Planned caesarean section at term versus planned vaginal birth for breech presentation at term: a randomised controlled multicentred trial. Term Breech Trial Collaborative Group. Lancet. 2000;356(9239):1375-83.

11. Petrovska K, Watts N, Catling C, Bisits A, Homer C. Supporting Women Planning a Vaginal Breech Birth: An International Survey. Birth 2016;43(4):353-7.

12. Petrovska K, Watts N, Catling C, Bisits A, Homer C. 'Stress, anger, fear and injustice': An international qualitative survey of women's experiences planning a vaginal breech birth. Midwifery. 2017;44:41-7.

13. NSW Ministry of Health. Maternity - Supporting Women Planning a Vaginal Breech Birth. Sydney: NSW Government; 2017.

14. Flint C, Poulengeris P, Grant A. The 'Know Your Midwife' scheme - a randomised trial of continuity of care by a team of midwives. Midwifery. 1989;5(1):11-6.

15. Hatem M, Sandall J, Devane D, Soltani H, Gates S. Midwife-led versus other models of care for childbearing women. Cochrane Database of Systematic Rev. 2008;4:CD004667.

16. Sandall J, Soltani H, Gates S, Shennan A, Devane D. Midwife-led continuity models versus other models of care for childbearing women. Cochrane Database of Systematic Reviews. 2016; Issue 9:Art. No.: CD004667. DOI: 10.1002/14651858.CD004667.pub4.

17. NHS England. Better Births: Improving outcomes of maternity services in England. A Five Year Forward View for maternity care: National Maternity Review. London: NHS England; 2016.

18. WHO. WHO recommendations on antenatal care for a positive pregnancy experience. $\mathrm{G}$ eneva: World Health Organization; 2016.

19. Dawson K, McLachlan H, Newton M, Forster D. Implementing caseload midwifery: Exploring the views of maternity managers in Australia - A national cross-sectional survey. Women and Birth. 2016;29(3):214-22.

20. Cummins A, Denney-Wilson E, Homer $C$. The experiences of new graduate midwives working in midwifery continuity of care models in Australia. Midwifery. 2015;31(4):438-44. 